

\title{
Effects of hemodynamic conditions and valve sizing on leaflet bending stress in self-expanding transcatheter aortic valve: An in vitro study
}

Viktória Stanová, Anne-sophie Zenses, Lionel Thollon, Lyes Kadem, Paul Barragan, Régis Rieu, Philippe Pibarot

\section{To cite this version:}

Viktória Stanová, Anne-sophie Zenses, Lionel Thollon, Lyes Kadem, Paul Barragan, et al.. Effects of hemodynamic conditions and valve sizing on leaflet bending stress in self-expanding transcatheter aortic valve: An in vitro study. Artificial Organs, 2020, 44 (7), 10.1111/aor.13654 . hal-03230563

\section{HAL Id: hal-03230563 \\ https://hal-amu.archives-ouvertes.fr/hal-03230563}

Submitted on 20 May 2021

HAL is a multi-disciplinary open access archive for the deposit and dissemination of scientific research documents, whether they are published or not. The documents may come from teaching and research institutions in France or abroad, or from public or private research centers.
L'archive ouverte pluridisciplinaire HAL, est destinée au dépôt et à la diffusion de documents scientifiques de niveau recherche, publiés ou non, émanant des établissements d'enseignement et de recherche français ou étrangers, des laboratoires publics ou privés. 


\section{Effects of Hemodynamic Conditions and Valve Sizing on Leaflet Bending Stress in Self- Expanding Transcatheter Aortic Valve: An In- vitro Study.}

Viktória STANOVÁ ${ }^{1}$,Eng, MsC; Anne-Sophie ZENSES, PhD ${ }^{1,2}$; Lionel THOLLON, PhD ${ }^{1}$; Lyes KADEM ${ }^{3}$; Paul BARRAGAN, MD ${ }^{4}$; Régis RIEU, PhD ${ }^{1}$; Philippe PIBAROT, DVM, PhD ${ }^{2}$

1. Laboratoire de Biomécanique Appliquée, UMR T24 Université Gustave Eiffel / Aix Marseille Université, Marseille, France

2. Quebec Heart and Lung Institute, Laval University, Quebec, Canada

3. Department of Mechanical Industrial and Aerospace Engineering, Concordia University, Montreal, QC, Canada

4. Clinique des Fleurs, Cardiologie interventionnelle, Ollioules, France 


\section{Abstract}

Objectives:

Transcatheter aortic valve (TAV) replacement has become a viable alternative to surgery for high and intermediate risk patients with severe aortic stenosis. This technology may extend to the younger and lower risk patients. In this population, long-term durability of the TAV is key. Increased leaflet mechanical stress is one of the main determinants of valve structural deterioration. This in vitro study aims at evaluating, leaflet bending stress (LBS) in the selfexpanding TAV for different valve sizes, stroke volumes (SV) and degrees of valve oversizing (OS).

\section{Methods:}

Three different sizes $(23,26,29 \mathrm{~mm})$ of CoreValve (CV) were tested on a pulse duplicator in annulus size ranging from 17 to $26 \mathrm{~mm}$. Leaflet bending stress and bending of the leaflet coaptation line in diastole (pin-wheeling index) were measured using high-speed camera imaging (1000 images/sec).

Results:

For each given CV and annulus size, geometric orifice area increased significantly with OS $(p<0.001)$ and SV $(p=0.001)$. LBS decreased with increasing prosthesis size and aortic annulus (AA) size while increasing with $S V(p<0.03)$. The largest value of peak LBS (3.79 MPa) was obtained with the CV $23 \mathrm{~mm}$ in AA of $17 \mathrm{~mm}$ (\%OS=35\%), SV $90 \mathrm{ml}$ and the smallest value (0.99 MPa) for the CV $29 \mathrm{~mm}$ in AA of $26 \mathrm{~mm}$ (\%OS=12\%), SV $30 \mathrm{ml}$. On multivariable analysis, LBS increased independently with larger OS, smaller AA size and higher SV. The pinwheeling index increased with decreasing AA size and increasing OS.

\section{Conclusions:}

Moderate valve OS, such as generally used for transcatheter aortic valve implantation, is associated with increased LBS during valve opening and closing, especially in small annuli. Hence, TAV OS may negatively impact long-term valve durability.

Keywords: Transcatheter aortic valve implantation, Leaflet bending stress, Pin-wheeling index, Hemodynamic performance, Sizing 


\section{Abbreviations}

AA

Cc

CV

EOA

GOA

OS

$\mathrm{PI}$

SV

TAV

TAVI
Aortic Annuli

Contraction Coefficient

CoreValve Medtronic

Effective Orifice Area

Geometric Orifice Area

Oversizing

Pin-wheeling index

Stroke volume

Transcatheter Aortic Valve

Transcatheter Aortic Valve Implantation 


\section{Introduction}

Valvular heart diseases, including aortic stenosis are among the most prevalent cardiovascular diseases in the high income countries after hypertension and coronary artery disease[1]. Transcatheter aortic valve implantation (TAVI) has become a valuable alternative to surgical aortic valve replacement in patients with high or intermediate surgical risk [2-4] . Because TAVI is currently tested in the low surgical risk population, the long-term durability of the valve becomes a key issue. Increased mechanical stress of the valve leaflets is one of the main determinants of structural deterioration of bioprosthetic valves. $[5,6]$

The most frequent complication of TAVI is the occurrence of paravalvular regurgitation. It is generally recommended to apply mild to moderate valve oversizing (OS, 5-20\% diameter oversizing[7]) in order to reduce the risk of paravalvular regurgitation or valve embolization. Valve oversizing leads however to an under-expansion of the TAV and we hypothesized that this will increase leaflet mechanical stress[8], the leading factor for structural valve deterioration of surgical bioprosthetic valves. Understanding of the dynamic mechanics exerted upon the aortic valve (pressure, bending stress, axial stress and shear stress) is crucial for the study of the biological pathways that regulate the valve deterioration. In order to investigate the bending deformations, a 2-D optical method has been developed to quantitate the degree of curvature and subsequent leaflet bending stress along the leaflet free edge[9].

The objective of this study is to examine the effects of aortic annulus size, valve size, degree of valve OS, and stroke volume on TAV hemodynamics and leaflet bending stress.

\section{Methods}

\section{In Vitro Cardiovascular Simulation.}

For the purpose of this study, a double activation left heart duplicator system[10] was used. This simulator is able to accurately mimic the human blood circulation from the pulmonary valve to the peripheral systemic capillaries by reproducing physiological pressure and flow waveforms. Briefly, the system includes anatomically shaped deformable silicon models of left ventricle and aorta. Contraction of the left ventricle was obtained using a ViVitro piston pump (ViVitro Inc., Victoria, Canada). Both pump activation and signal acquisition were controlled with LabVIEW8.2 (National Instruments, Texas, USA) through a Compact RIO with FPGA controller and DAQ acquisition system. Controlling enables physiological flow through the aortic valve following the standards for heart valve testing (ISO 5840-part 3[11]). In this study, the mitral valve inserted in the simulator was an Edwards Magna $29 \mathrm{~mm}$ and the aortic valve was a CoreValve with three different sizes. 
A saline glycerol solution fixed at $3.8 \pm 2 \mathrm{cP}$ at $37^{\circ} \mathrm{C}$ was used to mimic blood viscosity. Maintaining the temperature of the circulating fluid at $37^{\circ} \mathrm{C}$ was essential to ensure optimal radial force of the Nitinol-made $\mathrm{CV}$.

\section{Tested TAV Assemblies / Configurations.}

Three different sizes of the self-expanding CoreValve TAV were tested: $23 \mathrm{~mm}$ (CV 23), 26 $\mathrm{mm}$ (CV 26) and $29 \mathrm{~mm}$ (CV 29). The valves were implanted in custom-fabricated silicon models (Figure 1 and Online Erreur ! Source du renvoi introuvable.), with an internal diameter varying from 17 to $26 \mathrm{~mm}$ (Figure 2), in order to simulate the range of aortic annulus size in which those valves can be implanted in vivo. The CV 23 was implanted in annulus diameters of 17; 18; 19; $20 \mathrm{~mm}$, the CV 26 in annulus diameters of 20;21;22; $23 \mathrm{~mm}$ and the CV 29 in annulus diameters of 23; 24; 25; $26 \mathrm{~mm}$. Each TAV was deployed at the normal supra-annular deployment position.

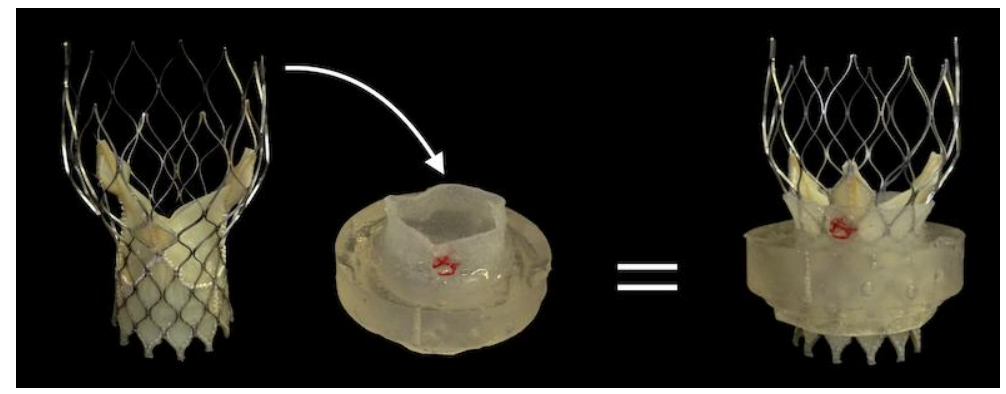

Figure 1 : Implantation of the TAV CoreValve in silicon aortic annuli. The CoreValve was implanted in custom-fabricated silicon aortic annulus. Each TAV was deployed at the normal deployment position (such as the valvular apparatus works in a supra-annular fashion).

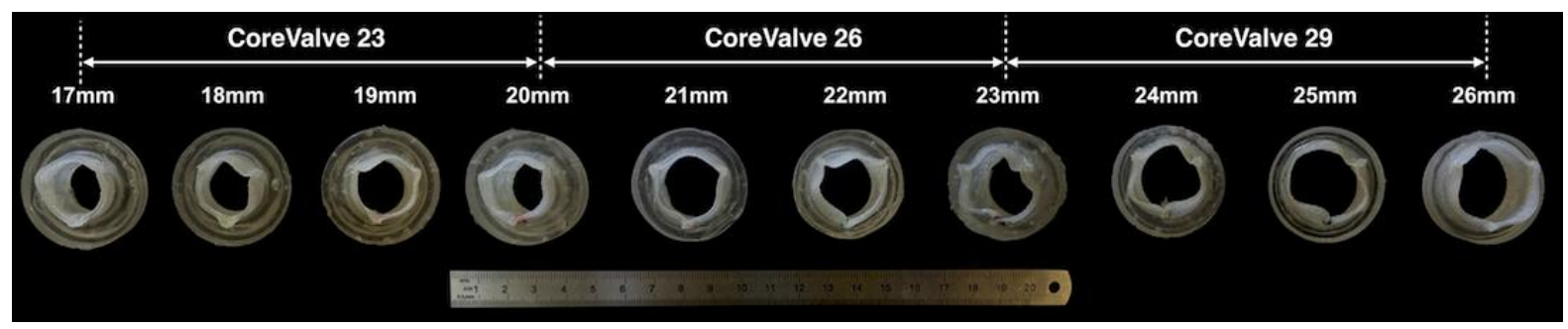

Figure 2 : Different annulus / TAV size configurations tested in this study.

To assess the degree of valve oversizing, we calculated the percentage of oversizing based on the diameter: \%OS= $100 \times$ (TAV nominal diameter - aortic annulus diameter) / aortic annulus diameter[12]. The \%OS corresponding to the different TAV size / annulus size configurations are presented in Tableau 0.1. 
Tableau 0.1 : TAV / annulus size configurations and corresponding \% of oversizing. AA, Aortic Annulus diameter; OS, oversizing

\begin{tabular}{|c|c|c|c|c|c|c|c|c|c|c|}
\hline & \multicolumn{4}{|c|}{ CoreValve 23} & & & & & & \\
\hline & & & & \multicolumn{4}{|c|}{ CoreValve 26} & & & \\
\hline & & & & & & & \multicolumn{4}{|c|}{ CoreValve 29} \\
\hline $\mathrm{AA}[\mathrm{mm}]$ & 17 & 18 & 19 & 20 & 21 & 22 & 23 & 24 & 25 & 26 \\
\hline $\begin{array}{c}\text { OS [\%] } \\
\text { diameter }\end{array}$ & 35 & 28 & 21 & 15 & 24 & 18 & $13 / 26$ & 21 & 16 & 12 \\
\hline
\end{tabular}

\section{Hemodynamic conditions.}

Each of the annulus/TAV size configurations was tested under the following experimental conditions (Tableau 0.2): four different stroke volumes were tested: $30 \mathrm{ml}, 50 \mathrm{ml}, 70 \mathrm{ml}$ and $90 \mathrm{ml}$. Heart rate was held constant at $70 \mathrm{bmp}$ and mean aortic pressure was held constant at $100 \mathrm{mmHg}$. In addition, in order to evaluate the independent effects of mean aortic pressure and heart rate, one set of experiments included a constant stroke volume held constant at $70 \mathrm{ml}$ and two different heart rates (70 bpm and $120 \mathrm{bpm}$ ) and mean aortic pressures (100 $\mathrm{mmHg}$ and $160 \mathrm{mmHg}$ ).

Tableau 0.2 : Experimental conditions.

\begin{tabular}{lll} 
Stroke volume $(\mathrm{ml})$ & Heart rate $(\mathrm{bpm})$ & Mean aortic pressure $(\mathrm{mmHg})$ \\
\hline 30 & 70 & 100 \\
\hline 50 & 70 & 100 \\
\hline 70 & 70 & 100 \\
70 & 120 & 100 \\
70 & 70 & 160 \\
\hline 90 & 70 & 100
\end{tabular}

Doppler echocardiographic measurements were performed using General Electric Vivid 7 system (GE Health Medical, Horten, Norway), with a phased array 3.5 MHz probe. The transvalvular flow velocities and aortic velocity-time integral were measured by continuouswave Doppler on five beats and averaged. Stroke volume was measured using an electromagnetic flowmeter Model 501 (Carolina Medical Electronics Inc., East Bend, USA, flowmeter calibration accuracy $\pm 5 \%$, linearity $\pm 1 \%$ maximum full scale) positioned immediately below the implanted prosthesis and averaged over 100 cycles. 
Valve effective orifice area (EOA) was calculated using the continuity equation, by dividing the stroke volume measured with the electromagnetic flowmeter by echocardiographic aortic velocity-time integral. The geometric orifice area (GOA) was obtained using a highspeed camera (SA3 Fastcam, Photron, Japan) by acquiring an en-face view of the valve during the cardiac cycle at a frame rate of 1000 images per second. Post-processing of the recorded images was done using a Matlab (Mathworks, Natick, MA, USA) code based on the work of Chan and Vese [13] and optimized for our application (Supplement 1 / Erreur ! Source du renvoi introuvable. Erreur ! Source du renvoi introuvable.).

\section{Leaflet bending stress.}

The bending stress of the leaflet free edge was estimated from the high speed camera recordings at different times during one cardiac cycle (Figure 3): 6 instants from fully closed to fully opened position (O0-Peak Systole), 1 instant in fully opened position and 6 instants from fully opened to fully closed position (C5-C0). The leaflet bending stress was estimated using the approach proposed by Corden et al. [9] (Supplement 2/Erreur! Source du renvoi introuvable. Erreur ! Source du renvoi introuvable.) and using by Maleki et al. [14].

$\mathrm{O} 3$

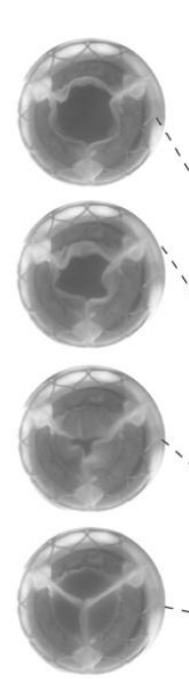

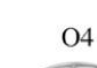
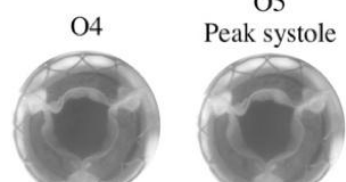
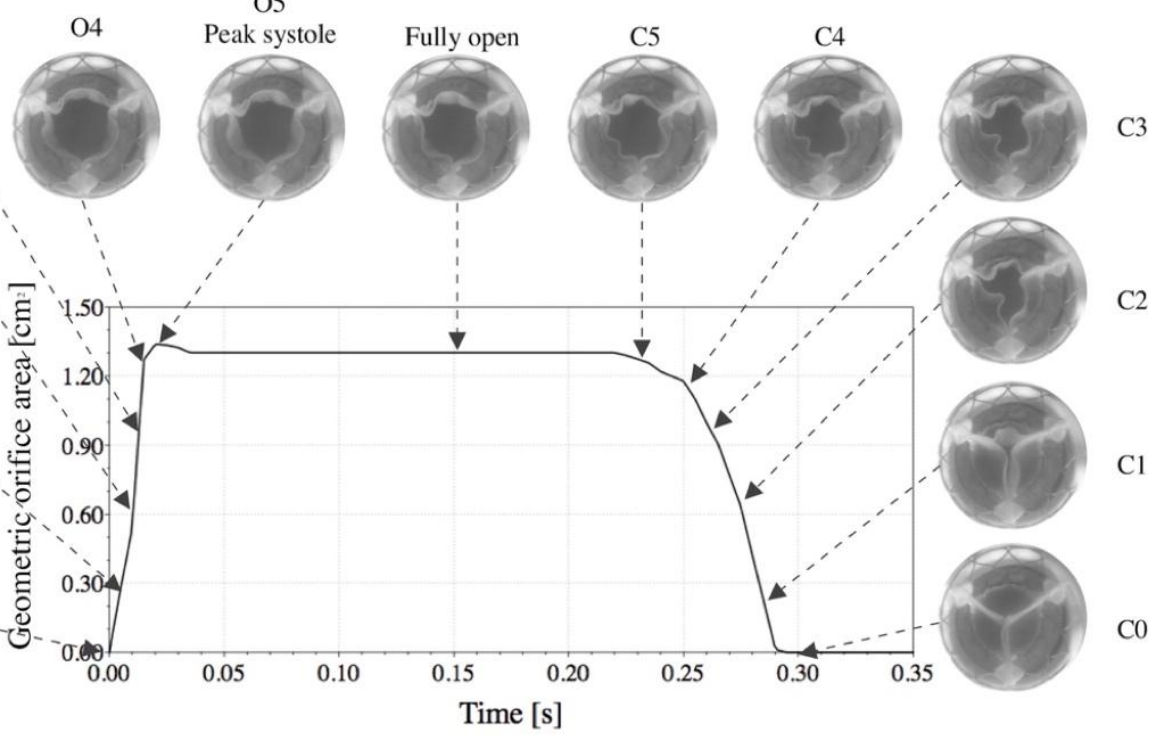

Figure 3 : Temporal changes in valve geometrical area as a function of time during one cycle. O: Opening; C: Closing.

\section{Pin-wheeling index.}

Pin-wheeling refers to a curvilineal deformation of a coaptation line between two leaflets in diastole. We evaluated the degree of pinwheeling by tracing the contour of a coaptation line and compared it to the unconstrained, ideal configuration (theoretically straight line) [12]. The pin-wheeling index (PI) was computed by the following equation: 


$$
P I=\frac{L_{\text {actual }}-L_{\text {ideal }}}{L_{\text {ideal }}}
$$

Determination of the pin-wheeling index was performed using a custom-made Matlab code after image calibration (Figure 4).

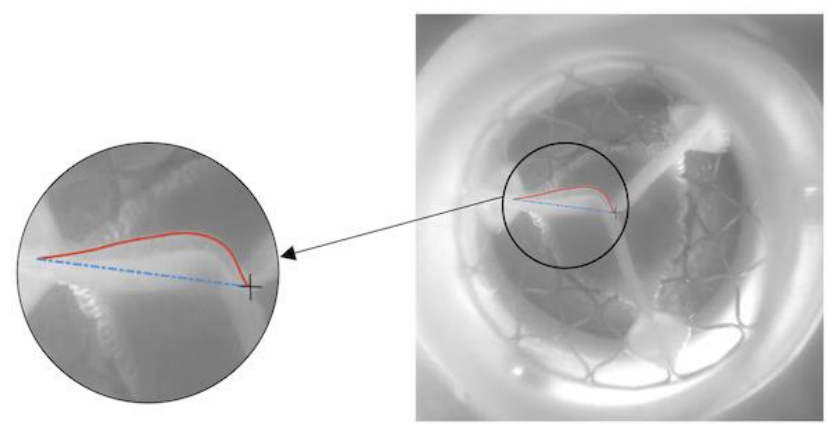

Figure 4 : Determination of the Pin-wheeling index.

\section{Statistical analysis.}

Continuous variables are presented as peak and mean values $\pm s d$. Mean values of leaflet bending stress were averaged over the 3 valve leaflets and the 13 instants of the cardiac cycle selected. Mean values of PI were averaged over the 3 coaptation lines of the closed valve. The values of leaflet bending stress and pin-wheeling index measured were compared using a one-way repeated ANOVA. The independent effects of CV size, aortic annulus size, $\% O S$, and stroke volume on EOA, GOA, leaflet bending stress and pinwheeling index were assessed using a forward stepwise multiple linear regression analysis and a $F$ value $\geq 4.0$ as the criterion for entry of the variable into the model.

The statistical analyses were performed using The R Project for Statistical Computing and a pvalue $<0.05$ was considered statistically significant.

\section{Results}

\section{Valve hemodynamics}

Tableau 0.3 reports univariable and multivariable determinants of CoreValve EOA. Univariable analysis shows that valve EOA correlates positively with $A A$ diameter $(R=0.844$; $p<0.001)$, prosthesis size $(R=0.802 ; p<0.001)$ and stroke volume $(R=0.491 ; p<0.001)$ but negatively with the level of valve oversizing $(R=-0.542 ; p<0.001)$. The negative correlation between EOA and the level of valve oversizing was mainly due to the AA size and therefore represent collinearity between ascending aortic size and oversizing (multivariate analysis did not show a significant association between valve oversizing and EOA). In the multivariable analysis, valve EOA variations are mainly and independently determined by AA diameter $\left(\Delta R^{2}=0.71 ; p<0.001\right)$ and stroke volume $\left(\Delta R^{2}=0.24 ; p<0.001\right)$. Similar findings were observed 
for the measured valve GOA (Online Erreur! Source du renvoi introuvable.) with a strong relationship with the AA diameter $\left(\Delta R^{2}=0.86 ; p<0.001\right)$. Interestingly, the ratio of valve EOA to valve GOA, the so-called contraction coefficient $(C \mathrm{C})$, correlates significantly and positively with the stroke volume $\left(p<0.001, R^{2}=0.87\right)$ but not with AA diameter $(p=0.48)$. Furthermore, Cc was found to vary significantly from 0.64 at low flow to 0.84 at high flow.

Tableau 0.3 : Univariable and Multivariable Determinants of TAV EOA.

Univariable Analysis

Multivariable Analysis

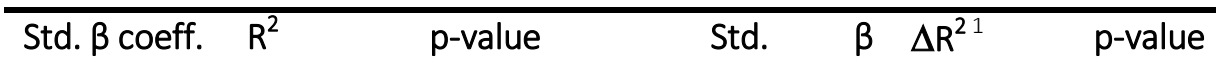

coeff.

\begin{tabular}{|c|c|c|c|c|c|c|}
\hline $\begin{array}{l}\text { AA diameter } \\
{[\mathrm{mm}]}\end{array}$ & 0.844 & 0.71 & $<0.001$ & 0.661 & 0.71 & $<0.001$ \\
\hline $\begin{array}{l}\text { Prosthesis size } \\
{[\mathrm{mm}]}\end{array}$ & 0.802 & 0.64 & $<0.001$ & 0.201 & 0.01 & 0.009 \\
\hline Oversizing [\%] & -0.542 & 0.29 & $<0.001$ & - & - & - \\
\hline $\begin{array}{l}\text { Stroke volume } \\
{[\mathrm{mL}]}\end{array}$ & 0.491 & 0.24 & $<0.001$ & 0.491 & 0.24 & $<0.001$ \\
\hline
\end{tabular}

\section{Valve leaflet bending stress}

\section{Effect of aortic annulus size, prosthesis size, OS, and stroke volume}

Figure 5 displays the time-averaged bending stress over a cardiac cycle under normal conditions ( $\mathrm{SV}=70 \mathrm{ml}$; HR=70 bpm and mean aortic pressure=100 $\mathrm{mmHg}$ ) for all the implantation configurations tested in this study. It appears that a higher degree of valve oversizing is associated with a more pronounced leaflet bending stress. Leaflet bending stress indeed increased significantly $(p<0.001)$ with decreasing annulus size, increasing TAV size (when implanted in the same size of $\mathrm{AA}$ ), and increasing \%OS.

When comparing two sizes of CV (23 and $26 \mathrm{~mm}$ ) implanted in a same $20 \mathrm{~mm}$ aortic annulus diameter under normal conditions (see Figure 5, red frame), marked oversizing (\%OS of 30\%) was associated with higher $(p<0.001)$ leaflet bending stress compared to modest oversizing (\%OS of 15\%): peak LBS 3.03 vs. $2.04 \mathrm{MPa}$ and mean LBS $0.26 \pm 0.07$ vs. $0.22 \pm 0.03 \mathrm{MPa}$. Similar results were found when the CV 26 and CV 29 were implanted in the same $23 \mathrm{~mm}$

\footnotetext{
${ }^{1} \Delta R^{2}$ coefficient represents the independent contribution of the variable to the variance of TAV Leaflet Bending Stress. The total $R^{2}$ of the multivariable model was 0.96 .
} 
aortic annulus diameter (\% OS: $13 \%$ vs. $26 \%$; see Figure 5, blue frame): $0.24 \pm 0.06$ vs. $0.17 \pm$ $0.07 \mathrm{MPa}$ for the mean value \pm standard deviation.



Figure 5 : Leaflet bending stress for all tested configurations in normal hemodynamic conditions. AA: Aortic Annulus diameter; HR: Heart Rate; MAP: Mean Aortic Pressure; OS: oversizing; SV: Stroke Volume; Red frame: two sizes of CV (23 and $26 \mathrm{~mm}$ ) implanted in the same $20 \mathrm{~mm}$ AA; Blue frame: two sizes of CV (26 and $29 \mathrm{~mm}$ ) implanted in the same $23 \mathrm{~mm}$ AA. For each assembly, values of leaflet bending stress were averaged over a cardiac cycle.

The smallest value of peak leaflet bending stress (0.99 MPa) was obtained with the CV $29 \mathrm{~mm}$ in $26 \mathrm{~mm}$ aortic annuli diameter (\%OS $=12 \%)$ at a stroke volume of $30 \mathrm{ml}$ and the largest value (3.79 MPa) for the CV $23 \mathrm{~mm}$ in $17 \mathrm{~mm}$ aortic annuli diameter (\%OS = 35\%) at a stroke volume of $90 \mathrm{ml}$. In the dataset including all TAV/annulus size configurations, the leaflet bending stress increased significantly with stroke volume in small CoreValve (CV $23 \mathrm{~mm}$ ) and small annuli size ( $p=0.02$ ) while this effect was not seen in large CVs implanted in large annuli size $(p=0.34)$ (Online Erreur! Source du renvoi introuvable.). As opposed to stroke volume, heart rate and mean aortic pressure did not lead to a significant increase in leaflet bending stress (Figure 6, Online Erreur! Source du renvoi introuvable.).

On multivariable analysis, larger \%OS $(p=0.03)$, smaller annulus size $(p<0.001)$ and to a lesser extent increased stroke volume $(p=0.05)$, were independently associated with higher leaflet bending stress during the cardiac cycle (Tableau 0.4). 


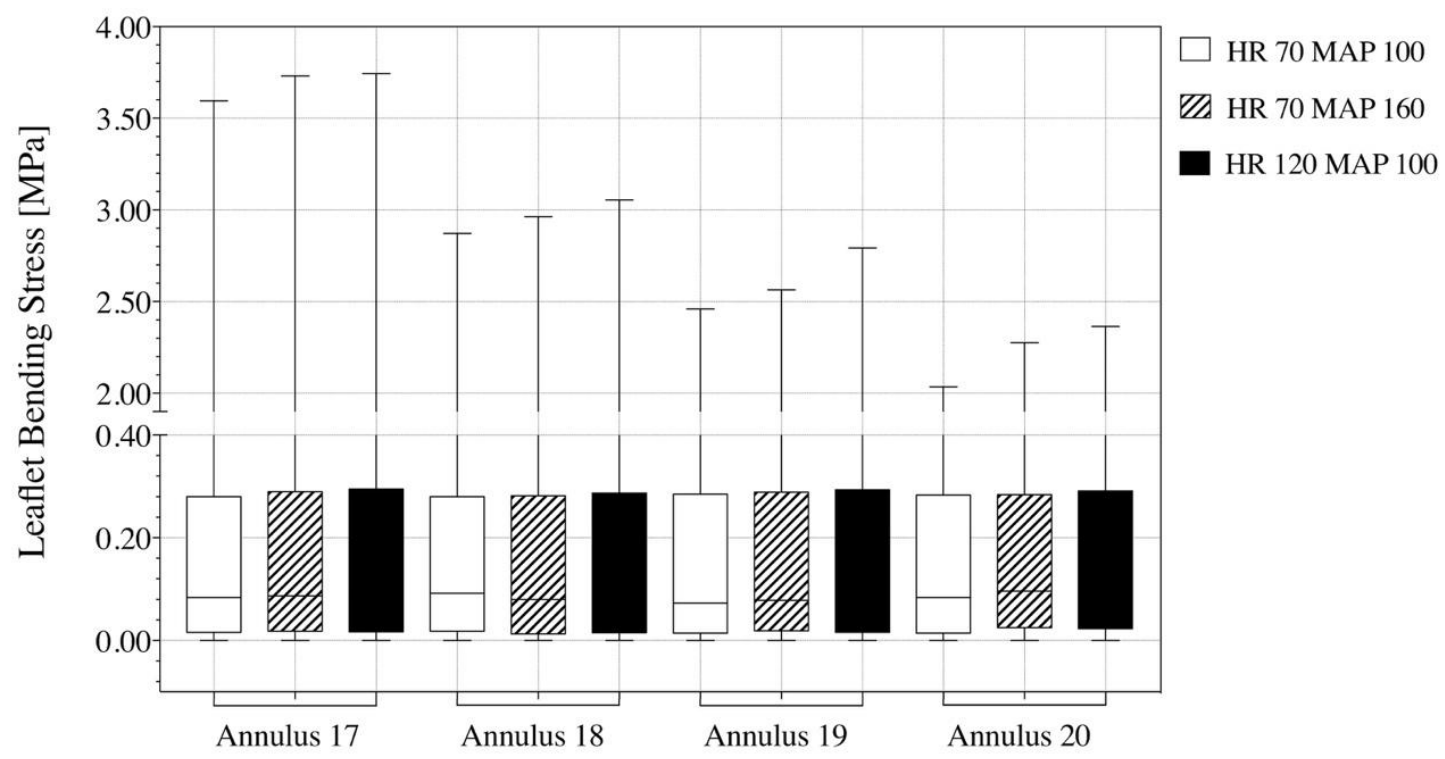

Figure 6 : Effects of heart rate and mean aortic pressure on the leaflet bending stress. HR, Heart Rate; MAP, Mean Aortic Pressure. For each assembly, values of leaflet bending stress were averaged over a cardiac cycle.

Tableau 0.4 : Univariable and Multivariable Determinants of TAV Leaflet Bending Stress Univariable Analysis Multivariable Analysis

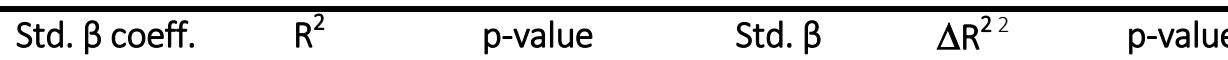
coeff.

\begin{tabular}{|c|c|c|c|c|c|c|}
\hline $\begin{array}{l}\text { AA diameter } \\
{[\mathrm{mm}]}\end{array}$ & -0.878 & 0.77 & $<0.001$ & -0.687 & 0.77 & $<0.001$ \\
\hline $\begin{array}{l}\text { Prosthesis size } \\
{[\mathrm{mm}]}\end{array}$ & -0.726 & 0.53 & $<0.001$ & - & - & - \\
\hline Oversizing [\%] & 0.755 & 0.57 & $<0.001$ & 0.270 & 0.04 & 0.03 \\
\hline $\begin{array}{l}\text { Stroke volume } \\
{[\mathrm{mL}]}\end{array}$ & 0.179 & 0.03 & 0.05 & 0.179 & 0.03 & 0.05 \\
\hline
\end{tabular}

\section{Localization and Timing of the peak leaflet bending stress.}

The peak of leaflet bending stress occurred during the valve opening (00-05) or closing phases (C5-C0) and not when the valve was fully open or fully closed (Figure 7). For all configurations, the peak LBS was found on the leaflet with the longest free edge, mainly during early valve opening or just before closing.

\footnotetext{
${ }^{2} \Delta R^{2}$ coefficient represents the independent contribution of the variable to the variance of TAV Leaflet Bending Stress. The total $R^{2}$ of the multivariable model was 0.84 .
} 
The location on a leaflet free edge of the peak bending stress varied during a cardiac cycle (Figure 7). At peak systole and fully open position, the valve leaflets all opened to a similar shape and exhibited areas of high curvature at the leaflet free edge close to the valve posts (commissures) and to a lesser extent in the middle of the leaflet free edge (Figure 8). At the early opening and closing phases, the stress was located mainly in the middle of the valve leaflet free edge.

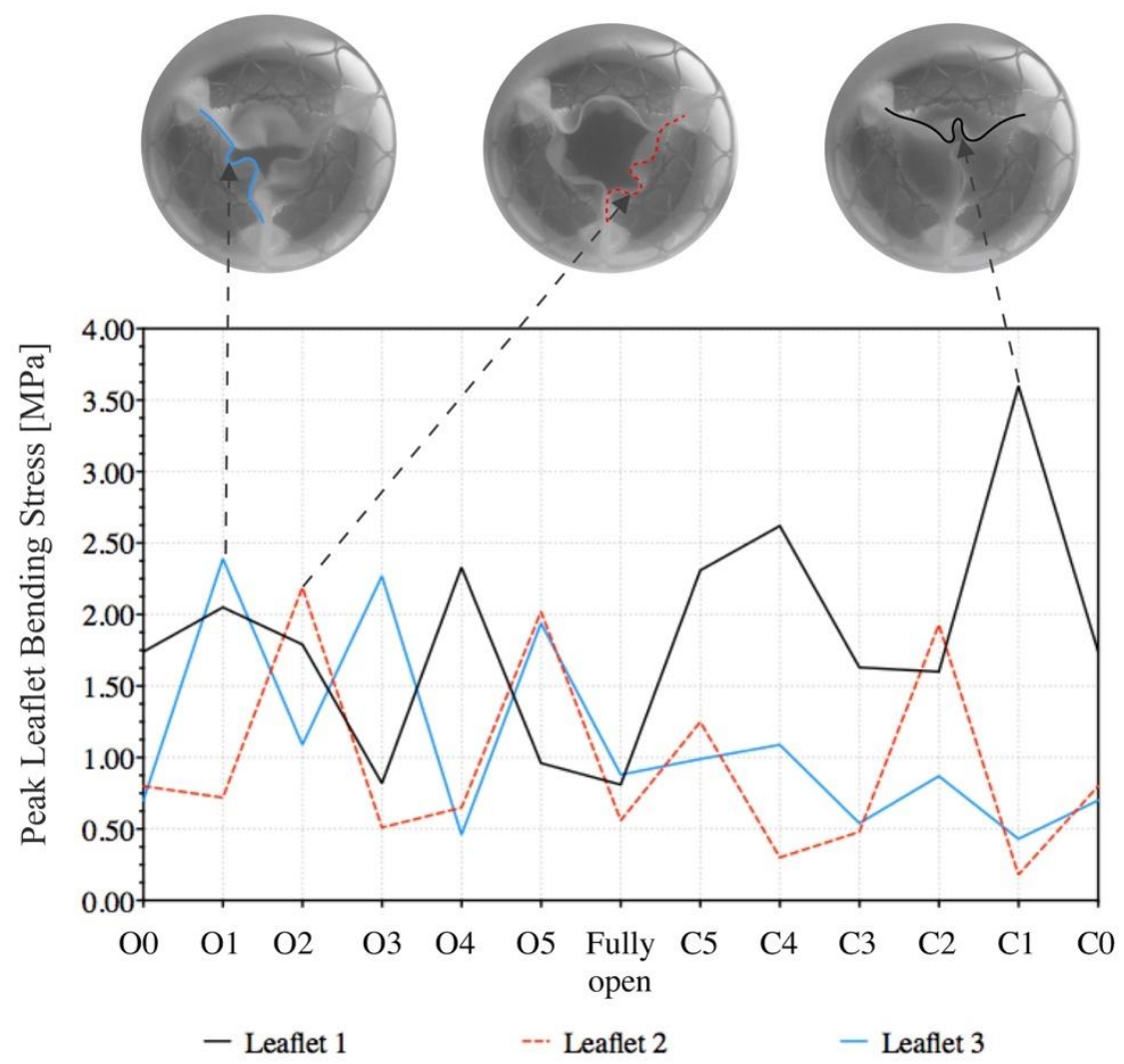

Figure 7 : Peak leaflet bending stress for each leaflet of CV $23 \mathrm{~mm}$ in AA $17 \mathrm{~mm}$ during one cardiac cycle in normal flow conditions. O: Opening; C: Closing.

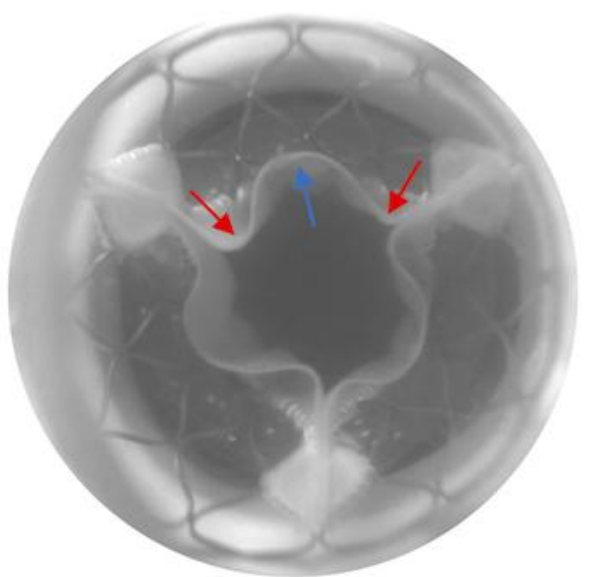

Figure 8 : Leaflet bending radii at fully opened position. Red arrows point out the zone close to the posts, the blue arrow shows the middle of the leaflet free edge. 


\section{Pin- wheeling index}

For a given $\mathrm{CV}$, the pin-wheeling index increased with decreasing aortic annulus size and increasing OS (Figure 9, Online Erreur ! Source du renvoi introuvable.). The CV 29 had the least amount of pin-wheeling when compared with other CV sizes ( 23 and $26 \mathrm{~mm}$ ) in all the deployment sizes $(p<0.01)$. The highest pin-wheeling index was found in $23 \mathrm{~mm} \mathrm{CV}$ implanted in a $17 \mathrm{~mm}$ aortic annulus and the lowest value was found in CV 29 implanted in a $26 \mathrm{~mm}$ aortic annulus (5.24 $\pm 0.05 \%$ vs. $1.96 \pm 0.01 \%)$. On multivariable analysis, only a larger $\% O S$ and smaller annulus size were independently associated with higher pin-wheeling index (Tableau 0.5).

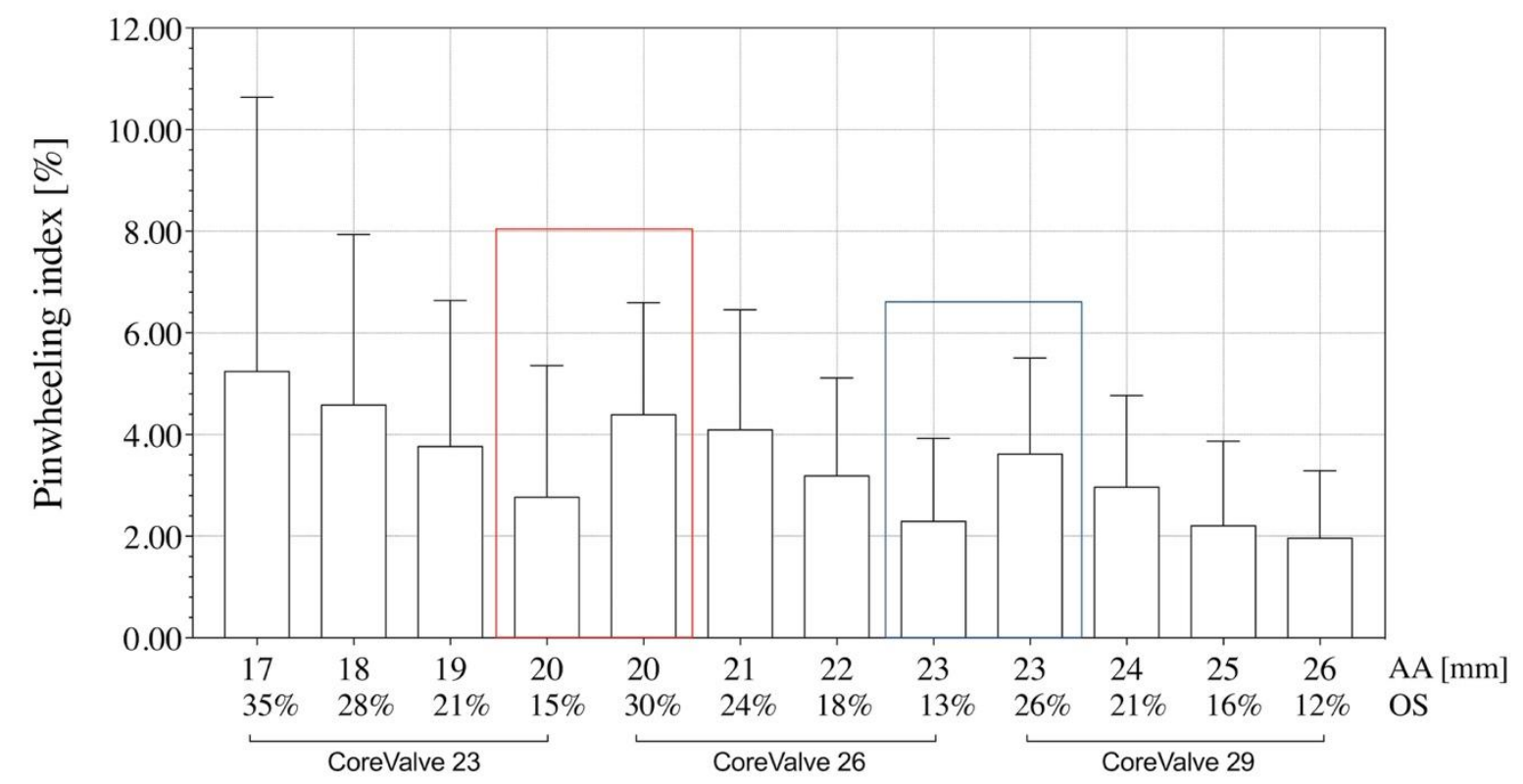

Figure 9 : Pin-wheeling index. AA, Aortic Annulus diameter; OS, oversizing; Red frame : two sizes of CV (23 and $26 \mathrm{~mm}$ ) implanted in same $20 \mathrm{~mm}$ AA; Blue frame: two sizes of CV (26 and $29 \mathrm{~mm}$ ) implanted in same $23 \mathrm{~mm}$ AA.

Tableau 0.5 : Univariable and Multivariable Determinants of TAV Pin-wheeling index.

Univariable Analysis

Multivariable Analysis

\begin{tabular}{llllll}
\hline Std. $\beta$ coeff. & $R^{2}$ & $p$-value & $\begin{array}{l}\text { Std. } \beta \\
\text { coeff. }\end{array}$ & $\Delta R^{23}$ & $p$-value \\
& & & \\
& & &
\end{tabular}

\begin{tabular}{lcccccc}
\hline $\begin{array}{l}\text { AA diameter } \\
\text { [mm] }\end{array}$ & -0.850 & 0.72 & $<0.001$ & -0.363 & 0.07 & $<0.001$ \\
$\begin{array}{l}\text { Prosthesis size } \\
\text { [mm] }\end{array}$ & -0.574 & 0.33 & $<0.001$ & - & - & - \\
Oversizing [\%] & 0.946 & 0.90 & $<0.001$ & 0.690 & 0.90 & $<0.001$
\end{tabular}

\footnotetext{
${ }^{3} \Delta R^{2}$ coefficient represents the independent contribution of the variable to the variance of TAV Leaflet Bending Stress. The total $R^{2}$ of the multivariable model was 0.97 .
} 


\section{Discussion}

In this study, we analyzed the deformations and associated leaflet bending stress observed at the leaflets free edges during a cardiac cycle as well as the pin-wheeling during closing phase . The main findings of our study are as follows: i) The EOA and the GOA in TAVs are flow dependent, i.e. low flow conditions (SV $<50 \mathrm{ml}$ ) may result in an incomplete valve opening and thus smaller EOA and GOA; ii) The EOA and GOA are influenced by aortic annulus size; iii) LBS was higher in case of increased \%OS whether through smaller annulus size or larger CV size at fixed CV and annulus size respectively.; iv) Higher stroke volumes are associated with higher leaflet bending stress, whereas heart rate and mean aortic pressure have no significant effect; v) Peak values of LBS occur during valve opening or closing phases but not necessarily when the valve is fully open; vi) The peak values of LBS were found on the leaflet with the longest free edge; vii)The degree of leaflet pin-wheeling during valve closing was increased with decreasing aortic annulus size, increasing valve size, and increasing OS but was not influenced by stroke volume or aortic pressures.

During an average human lifetime the aortic valve may open and close $3 \times 10^{9}$ times[15]. During each cycle, the valve leaflets are exposed to physiologic stresses of bending and to the mechanical trauma of coaptation. The most significant stresses are tension during diastole and flexion during valve opening and closing. High mechanical stress (i.e. high levels of curvature cause high bending stress) is one of the main causative factors in the structural deterioration of native and bioprosthetic valves[16,17] .

Bending stress is defined as the stress generated on a solid when it is deformed under flexion. Precisely, in the valve, bending stress causes the fibrosa layer (concave layer) to be compressed whereas the convex ventricularis layer is under tension[18]. Pin-wheeling refers to a torsion motion of the leaflets during closure. Higher bending stress and pin-wheeling deformation of the valve leaflets have been associated with increased fatigue and accelerated failure of the bioprosthetic leaflets[11]. According to ISO 5840-3:2013 heart valve guidelines, localized bending of leaflet material or pin-wheeling are associated with faster structural valve deterioration and should thus be avoided [12]. There are very few data on TAV leaflet stress and deformation and these studies mostly used predictive models using finite element analyses[19,20]. Numerical analyses of TAV leaflets could be difficult and incomplete due to the complex material properties and variable leaflet geometries that can occur. Moreover, there are very few methods that analyzes the stresses during normal function of the leaflets in vivo[21]. Thanks to recent clinical imaging techniques (cardiac ultrasound, computed tomography), that have allowed the generation of anatomically 
correct and time-resolved geometric models of the aortic valve, a simplified approach could be applied in order to obtain a reasonable approximation of the leaflet mechanical stress rapidly. One such method could be the leaflet bending stress assessment.

In the present in vitro study simulating TAV implantation in different sizes of aortic annuli, we observed that peak and mean TAV leaflet bending stress of the CV were in the same range as in two other in-vitro studies (evaluating stresses in polyurethane valves [9] and SAPIEN TAV [14]), and a finite element analysis study [22].

Mild to moderate (5-20\% area oversizing) valve oversizing is recommended to prevent valve embolization and paravalvular regurgitation following TAVI $[7,23]$. The results of this study show that more important oversizing, using a 26 rather than a $23 \mathrm{~mm}$ and the 29 rather than $26 \mathrm{~mm}$ CoreValve (in AA $20 \mathrm{~mm}$ and AA $23 \mathrm{~mm}$ respectively), is associated with larger EOAs and GOAs.

TAVI within the failed aortic surgical BP, i.e. valve-in-valve procedure, is associated with important oversizing, mostly in small surgical BP. Even more important oversizing, using a 26 rather than a $23 \mathrm{~mm}$ CoreValve, was associated with somewhat larger EOAs and lower gradients with the Trifecta $21 \mathrm{~mm}$ and the Epic Supra $21 \mathrm{~mm}$ but not with the Mitroflow $21 \mathrm{~mm}$ [24]. In the mitral valve-in-valve study, an internal orifice diameter $<22 \mathrm{~mm}$ was associated with higher risk of significant mitral stenosis, particularly when the oversizing was $>20 \%$, and internal orifice diameter $>23 \mathrm{~mm}$ was associated with higher risk of paravalvular regurgitation when oversizing was $<8 \%$ [25].

The leaflet bending stress and pin-wheeling increase significantly with larger degrees of TAV oversizing, especially when $>20 \%$. These findings suggest that patients with moderate to important OS may be predisposed to accelerated structural valve deterioration. These patients may thus require a closer clinical and Doppler-echocardiographic follow-up. With the new generations of TAVs such as the EvolutR PRO, SAPIEN 3, prevention of valve paravalvular regurgitation can be achieved with lesser degrees of oversizing thus potentially reducing the levels of leaflet mechanical stress and the risk of structural deterioration. In the context of transcatheter valve-in-valve procedure within failed surgical bioprostheses, the degree of TAV OS is often important, which may predispose accelerated TAV structural deterioration and thus limited durability of the valve-in-valve. The results of our study also suggest that longer length of the leaflet free edge may be associated with increased bending stress and potentially reduce the valve durability.

Prosthesis-patient mismatch occurs when the patient's cardiac output requirements are too high in relation with the prosthetic valve effective orifice area. Larger stroke volume was associated with increased leaflet bending stress in the present study. Furthermore, prosthesis-patient mismatch occurs more often in patients with a small aortic annulus, which is also associated with increased LBS[26]. Hence, these results may provide a mechanistic 
explanation to the previously reported association between prosthesis-patient mismatch and higher risk of structural valve deterioration following surgical valve replacement with a bioprosthetic valve[27,28].

\section{Study Limitations}

In this study, the impact of valve oversizing on hemodynamics and leaflet bending stress has been investigated only for the first generation of the auto-expandable transcatheter aortic valve CoreValve. Hence, the results of this study cannot be directly transposed to the newer generations of this type of valve (CV Evolut R or CV Evolut R PRO) or to the other types of TAVs. The annuli tested in this study had "ideal circular contours". In vivo, bicuspid valve phenotype and presence of calcification nodules at the level of aortic annulus often yields to non-circular[29] and irregular annulus cross-sectional shape, which may be associated with increased leaflet mechanical stress, and therefore reduced long-term durability of the TAV. In addition, the CoreValve was tested only in the supra-annular position as recommended clinically, and not in intra-annular or high supra-annular position, which could also have an effect on the valve deployment and the leaflet bending stress.

\section{Conclusion}

Valve OS as often recommended for TAVI is associated with higher LBS and pin-wheeling index, especially in the small aortic annulus. Hence, larger OS may predispose to accelerated structural valve deterioration following TAVI. Higher stroke volume may also increase LBS, which may explain the previously reported association between prosthesis-patient mismatch and structural valve deterioration. New generations of TAV that allow less OS may be associated with less leaflet mechanical stress and deformation, and thus longer durability.

\section{Impact on daily practice}

This method provides a useful information that may provide a mechanistic explanation for the association between valve oversizing and higher risk of structural valve deterioration following the valve replacement with a bioprosthetic valve. 


\section{References}

1. Baumgartner H. Aortic stenosis: medical and surgical management. Heart. 2005;91:14838.

2. Kapadia SR, Leon MB, Makkar RR, Tuzcu EM, Svensson LG, Kodali S, Webb JG, Mack MJ, Douglas PS, Thourani VH, Babaliaros VC, Herrmann HC, Szeto WY, Pichard AD, Williams MR, Fontana GP, Miller DC, Anderson WN, Smith CR, Akin JJ, Davidson MJ. 5-year outcomes of transcatheter aortic valve replacement compared with standard treatment for patients with inoperable aortic stenosis (PARTNER 1): a randomised controlled trial. The Lancet. 2015;385:2485-91.

3. Leon MB, Smith CR, Mack MJ, Makkar RR, Svensson LG, Kodali SK, Thourani VH, Tuzcu EM, Miller DC, Herrmann HC, Doshi D, Cohen DJ, Pichard AD, Kapadia S, Dewey T, Babaliaros V, Szeto WY, Williams MR, Kereiakes D, Zajarias A, Greason KL, Whisenant BK, Hodson RW, Moses JW, Trento A, Brown DL, Fearon WF, Pibarot P, Hahn RT, Jaber WA, Anderson WN, Alu MC, Webb JG. Transcatheter or Surgical Aortic-Valve Replacement in Intermediate-Risk Patients. N Engl J Med. 2016;374:1609-20.

4. Reardon MJ, Van Mieghem NM, Popma JJ, Kleiman NS, Søndergaard L, Mumtaz M, Adams DH, Deeb GM, Maini B, Gada H, Chetcuti S, Gleason T, Heiser J, Lange R, Merhi W, Oh JK, Olsen PS, Piazza N, Williams M, Windecker S, Yakubov SJ, Grube E, Makkar R, Lee JS, Conte J, Vang E, Nguyen H, Chang Y, Mugglin AS, Serruys PWJC, Kappetein AP. Surgical or Transcatheter Aortic-Valve Replacement in Intermediate-Risk Patients. N Engl J Med. 2017;376:1321-31.

5. Sun W. Simulated Bioprosthetic Heart Valve Deformation under Quasi-Static Loading. J Biomech Eng. 2005;127:905.

6. Martin C, Sun W. Simulation of long-term fatigue damage in bioprosthetic heart valves: effects of leaflet and stent elastic properties. Biomech Model Mechanobiol. 2014;13:75970.

7. Mylotte D, Martucci G, Piazza N. Patient selection for transcatheter aortic valve implantation: An interventional cardiology perspective. Ann Cardiothorac Surg. 2012;1:206-15.

8. Abbasi M, Azadani AN. Leaflet stress and strain distributions following incomplete transcatheter aortic valve expansion. J Biomech. 2015;48:3663-71.

9. Corden J, David T, Fisher J. Determination of the curvatures and bending strains in open trileaflet heart valves. Arch Proc Inst Mech Eng Part H J Eng Med 1989-1996 Vols 203210. 1995;209:121-8.

10. Tanné $D$, Bertrand E, Kadem L, Pibarot P, Rieu R. Assessment of left heart and pulmonary circulation flow dynamics by a new pulsed mock circulatory system. Exp Fluids. 2010;48:837-50.

11. International Standards Organization, editor. Part 3: Heart valve substitutes implanted by transcatheter techniques. ISO 5840-32013 Cardiovasc. Implants - Card. Valve Prostheses, Geneva, Switzerland: 2013.

12. Midha PA, Raghav V, Condado JF, Okafor IU, Lerakis S, Thourani VH, Babaliaros V, Yoganathan AP. Valve Type, Size, and Deployment Location Affect Hemodynamics in an In Vitro Valve-in-Valve Model. JACC Cardiovasc Interv. 2016;9:1618-28.

13. Chan TF, Vese LA. Active contours without edges. IEEE Trans Image Process. 2001;10:266-77. 
14. Maleki H, Shahriari S, Labrosse M, Rodés-Cabau J, Pibarot P, Kadem L. Effect of Aortic Annulus Size and Prosthesis Oversizing on the Hemodynamics and Leaflet Bending Stress of Transcatheter Valves: An In Vitro Study. Can J Cardiol. 2015;31:1041-6.

15. Bonet T. Sepulchretum sive Anatomica Practica. Geneva: Cramer and Perachon; n.d.

16. Robicsek F, Thubrikar MJ. Mechanical Stress as Cause of Aortic Valve Disease Presentation of a New Aortic Root Prosthesis. Acta Chir Belg. 2002;102:1-6.

17. Thubrikar M, Bosher LP, Nolan SP. The mechanism of opening of the aortic valve. J Thorac Cardiovasc Surg. 1979;77:863-70.

18. Chester AH, El-Hamamsy I, Butcher JT, Latif N, Bertazzo S, Yacoub MH. The living aortic valve: From molecules to function. Glob Cardio/ Sci Pract. 2014;2014:11.

19. Smuts AN, Blaine DC, Scheffer C, Weich H, Doubell AF, Dellimore KH. Application of finite element analysis to the design of tissue leaflets for a percutaneous aortic valve. $J$ Mech Behav Biomed Mater. 2011;4:85-98.

20. Thubrikar M. The aortic valve. London: Informa; 2011.

21. Thubrikar MJ, Skinner JR, Eppink RT, Nolan SP. Stress analysis of porcine bioprosthetic heart valvesin vivo. J Biomed Mater Res. 1982;16:811-26.

22. Xuan Y, Krishnan K, Ye J, Dvir D, Guccione JM, Ge L, Tseng EE. Stent and leaflet stresses in a 26-mm first-generation balloon-expandable transcatheter aortic valve. J Thorac Cardiovasc Surg. 2017;153:1065-73.

23. Dvir D, Webb JG, Piazza N, Blanke P, Barbanti M, Bleiziffer S, Wood DA, Mylotte D, Wilson $A B$, Tan J, Stub D, Tamburino C, Lange R, Leipsic J. Multicenter evaluation of transcatheter aortic valve replacement using either SAPIEN XT or CoreValve: Degree of device oversizing by computed-tomography and clinical outcomes: Oversizing in TAVR. Catheter Cardiovasc Interv. 2015;86:508-15.

24. Zenses A-S, Evin MA, Stanová V, Clavel M-A, Barragan P, Rodés-Cabau J, Obadia J-F, Pibarot $P$, Rieu R. Effect of size and position of self-expanding transcatheter valve on haemodynamics following valve-in-valve procedure in small surgical bioprostheses: an in vitro study. Eurolntervention. 2018;14:e282-9.

25. Evin M, Guivier-Curien C, Rieu R, Rodés-Cabau J, Pibarot P. Mitral valve-in-valve hemodynamic performance: An in vitro study. J Thorac Cardiovasc Surg. 2016;151:10511059.e6.

26. Pibarot P, Magne J, Leipsic J, Côté N, Blanke P, Thourani VH, Hahn R. Imaging for Predicting and Assessing Prosthesis-Patient Mismatch After Aortic Valve Replacement. JACC Cardiovasc Imaging. 2019;12:149-62.

27. Flameng W, Herregods MC, Vercalsteren M, Herijgers P, Bogaerts K, Meuris B. ProsthesisPatient Mismatch Predicts Structural Valve Degeneration in Bioprosthetic Heart Valves. Circulation. 2010;121:2123-9.

28. Mahjoub H, Mathieu P, Larose E, Dahou A, Sénéchal M, Dumesnil J-G, Després J-P, Pibarot P. Determinants of aortic bioprosthetic valve calcification assessed by multidetector CT. Heart. 2015;101:472-7.

29. Salaun E, Zenses A-S, Evin M, Collart F, Habib G, Pibarot P, Rieu R. Effect of oversizing and elliptical shape of aortic annulus on transcatheter valve hemodynamics: An in vitro study. Int J Cardiol. 2016;208:28-35. 